\title{
SQUARING THE CARTESIAN CIRCLE
}

Charles Huenemann

University of Illinois at Chicago

The lasting objection against Descartes's Meditations seems to be that his reasoning is circular. On the one hand, he uses reasons which he calls "clear and distinct" to prove God's existence; and on the other hand, he uses God's perfection (and hence God's inability to deceive) as justification for the validity of these clear and distinct reasons. Or else the circularity is in his understanding of God's nature: he must perceive God's nature clearly and distinctly in order to see that God can be no deceiver, yet he needs to prove that God is no deceiver before he can trust what he clearly and distinctly perceives.

Of course the nagging question is: how could Descartes have failed to notice this apparent difficulty? This question is especially acute since in his dedicatory letter Descartes tells the theologians that it is of course true that

we must believe in the existence of Cod because it is a doctrine of Holy Scripture, and, conversely, that we must believe Holy Scripture because it comes from God.... But this argument cannot be put to unbelievers because they would judge it to be circular.?

Descartes thinks he has a better way to convince the unbelievers: he thinks the existence of God and the distinction of the soul from the body can be shown by reasoning which is common to us all. But can Descartes be found innocent of the apparent circularity of the Third Meditation?

I think he can. In this essay I will argue that Descartes indeed uses the existence and perfection of God to insure that everything he clearly and distinctly perceives is true. But he does not base his argument for God's existence and perfection on the truth of everything he clearly and distinctly perceives. Instead, he bases his argument on the light of nature, which is quite different. The linearity of Descartes's reasoning is thus from the light of nature to the existence and perfection of God, and then to the validity of clear and distinct perception.

Why be interested in the Meditations construed this way? After all, there is some appeal to the project of demonstrating all knowledge from no presuppositions whatsoever; and according to my construal, Descartes has a very heavy presupposition: the veracity of the light of nature. The main

1 AT VIl 2. All translations in this essay are from The Philosophical Writings of Descartes, translated by Cottingham, Stoothoff, Murdoch, and Kenny (Cambridge: Cambridge University Pres, 1991). 
reason of interest is that, as I will argue, it is inconceivable to embark on any effort such as the Meditations without presupposing something like the light of nature. Moreover, everything shown to Descartes by the light of nature can plausibly be supposed to be common to any rational being. If Descartes is trying to find a common base from which to reach conclusions everyone should accept about God and the soul, the light of nature is a good candidate for that common base.

Now I also believe that Descartes was not just interested in proving matters about God and the soul; more subtly, he was trying to convert his Aristotelian readers to the new physics. My argument, in addition to squaring the Cartesian circle, will illuminate the way in which Descartes tried to accomplish this.

Our discussion breaks into three parts. First, I will introduce "the three doubts," which I believe essential in setting the stage for the Meditations. Second, I will examine the argument in the Third Meditation for the existence of God, determining whether Descartes's rcasoning is circular, and whether Descartes indeed presupposes the validity of everything he clearly and distinctly perceives. Finally, I will suggest that Descartes's presupposal of the light of nature helps to make clear a central motivation in writing the Meditations: Descartes wished to show, by reasoning common to us all, that his mechanistic physics is more certain than Aristotelian physics, and not the least bit heretical.

Part 1: The three doubts

Once Descartes secures for himself the leisure for philosophical reflection, he begins to attack the principles which support everything he has believed up to this point in his life. He renders these principles insufficient by describing possible situations in which his beliefs are false but nevertheless understandably believed by him. ${ }^{2}$ He describes three such situations, and I believe it is important that we keep them distinct.

First, Descartes remarks that his senses often deceive him about small or distant things. But he finds that he could also doubt his sensory evidence of big or close things, were he to assume that he was similar to insane people, who "say they are dressed in purple when they are naked, or that their heads are made of earthenware, or that they are pumpkins, or made of glass." 3 Yet he briskly (and sarcastically) rejects this possibility: he says he would be crazy to take seriously the suggestion that he might be crazy. For, we may venture, were he to take this doubt seriously, not only would his senses be called into doubt, but also his reasoning capacity in its entirety. And if he cannot trust any part of his reasoning capacity, the

2 For detailed discussion of the dynamics of this process, see Edwin Curley, Descartes Against the Skeptics (Cambridge: Harvard UP, 1978).

3 AT VII 19. 
Meditations come to an abrupt halt; for how can I reason myself out of the supposition that I might be crazy?

Let us consider this more carefully. Suppose I set out on Descartes's path, to doubt everything I have hitherto believed, but I take seriously the doubt that I might be crazy. What survives this doubt? Can I reach the cogito? Can I be sure, first of all, that I think, or that I doubt? It certainly seems to me that I think. And it seems to me that anything which has the impression of seeming to think must first of all exist. But it seems to crazy people that their heads are made of earthenware. Why should my "seeming" be better off than their "seeming"? We might object that even these crazy people presuppose that they are thinking, and hence that they exist. But suppose some crazy person denies even this. Let us say it seems to them as if they do not exist at all. What objection can we bring to them? We cannot say that they must believe that they at least exist, on pain of being irrational, for, under the current supposition, they are irrational. And if we suppose that we may be irrational, nothing we think will ever prove that it is otherwise. This is, of course, because no proof will be effective upon anyone who cannot trust their own reason.

Indeed, we see that Descartes must presuppose his own rationality in order to undertake this process of doubting. For his plan is to describe possible situations in which his beliefs are false but nevertheless understandably believed by him. But it takes reason to sort out what is possible from what is not, and it takes reason to discern when a belief is nevertheless understandably believed by him. 4 Thus Descartes cannot take seriously the doubt that he is insane, lest his whole endeavor become incoherent.

So instead of supposing insanity on his part, Descartes supposes that, for all he knows, he may be dreaming while seeming to sense big or close things. This is his second doubt. He could be deceived in perceiving his chair, fireplace, and writing paper, and even in perceiving his eyes, head, and hands.

Let us understand this dreaming scenario as casting doubt upon our beliefs about "ordinary objects. $n$ Descartes identifies these objects as the objects studied by physics, astronomy, medicine, and, in short, all of the not purely mathematical sciences.

But Descartes finds even in his dreams some elements that he cannot in any obvious way be deceived about. The basic elements which compose dreamt objects seem certain and indubitable. Descartes writes

This class appears to include corporeal nature in general, and its extension; the shape of extended things; the

4 For this reason, I take my construal not to contradict Curley's way of straightening out the circle, but instead to supplement it. See Curley, loc. cit. 
quantity, or size and number of these things; the places in which they may exist, the time through which they may endure, and so on. 5

These objects aren't quite ordinary; rather, they are objects presupposed by ordinary objects. This class of special objects we may appropriately entitle "mathematical objects" since Descartes makes clear that they are the objects of study for "arithmetic, geometry, and other subjects of this kind."

Descartes finds that he can doubt his knowledge of mathematical objects upon the supposition that he is deceived by God, or by a malevolent demon. This is his third doubt. Upon this supposition, Descartes is forced to admit that "there is not one of my former beliefs about which a doubt may not properly be raised." 6 For our purposes it is important to bear in mind the distinctions among the objects doubted by the three scenarios: objects of reason (or simply reason) would be doubted, were Descartes to take seriously the thought that he might be crazy; ordinary objects are doubted in the dream scenario; and mathematical objects are doubted in the deceiving-demon scenario.

Part 2: The argument for God's existence and perfection

Before sketching the central argument of the Third Meditation, we need to remind ourselves what Descartes is certain of: that is, we need to know what his argument will presuppose. I will argue that everything Descartes presupposes is claimed by him to be shown by the light of nature; and, further, that Descartes indeed takes everything shown by the light of nature to be indubitably true. I will also show that, in particular, Descartes does not presuppose that everything he clearly and distinctly perceives is true.

I count three presuppositions to Descartes's argument for the existence of God. First, Descartes's argument will certainly presuppose the cogito. From the cogito we know that there is a thinking thing (namely, me) and that there are ideas, i.e., there are things the thing thinks. We do not know whether there is anything real which corresponds to those ideas, except for the idea of myself as a thinking thing. Necessarily, I exist whenever I think.

The cogito is certainly taken by Descartes to be shown by the light of nature. In fact, his first mention of the light of nature is in the Third Meditation, and makes explicit appeal to the cogito:

5 AT VII 20. In anticipation of part 3, we may note that these are precisely the notions Descartes employs in his laws of motion.

6 AT VII 21. 
Whatever is revealed to me by the natural light-for example, that from the fact that I am doubting it follows that I exist, and so on-cannot in any way be open to doubt. This is because there cannot be any other faculty both as trust worthy as the natural light and also capable of showing me that such things are not true.?

Note that this passage boldly asserts that nothing shown by the light of nature can be doubted; I take this to mean that, according to Descartes at this stage at least, it is impossible within reason to doubt the light of nature.

At this point it is profitable to consider the status of the light of nature. What did the light of nature mean to Descartes? John Morris argues that Descartes thought of the light of nature as a faculty of the human soul. ${ }^{8}$ According to Morris's Descartes, the soul has an active part (the will) and a passive part (the understanding). The understanding, considered in itself, also has an active and a passive part. The active part generates concepts-and this is where clear and distinct perception of ideas comes in. The passive part is able only to recognize an element of truth or falsity in ideas-an oracle of sorts. This is the light of nature.

But how can we today understand the light of nature? Most liberally we might understand it as a discerner of analytic truths. That is, the light of nature is able to determine whether the predicate is included within the subject in a given proposition. But this is only partly helpful, since the cogito is not clearly an analytic truth. Nevertheless, there is some analytic connection between the proposition that $I$ think and the proposition that I exist.

We may wish to identify the light of nature with reason. But then we need to know exactly what reason is. It will not do to identify the light of nature with logic, since not even the cogito is shown be mere syllogistic logic. Nor will it do to suggest that the light of nature yields all the truths which are indubitable under every hypothesis, since no claim is indubitable under the hypothesis that we are insane. We might suggest that the light of nature gives us all truths which are indubitable under every hypothesis short of the hypothesis that we are insane. But we then need a nontrivial criterion of insanity-a criterion that does not appeal to the light of nature. I have come to believe that the light of nature must be taken primitively; it is for Descartes a "fixed point," grounding every possible investigation by rational agents. To be able to give an account of it would be to deny it of this fundamental status.

\footnotetext{
7 AT VII 38-9.

8 "Descartes's Natural Light", Journal of the History of Philosophy, v. 11, 1973.
} 
The second presupposition for Descartes's argument for God's existence and perfection is that $I$ have privileged access to my own ideas. While what seems to me to refer might not actually refer, it is nevertheless certain that what seems to seem to me to refer does indeed seem to me to refer. (One might say that ideas are closed under the "seeming" relation.) That is, what seems to be an idea in me is an idea in me. This is just to say that I cannot be wrong in my first-person psychological (or ideational) reports: I know my own ideas.

My knowledge of my own ideas is where clear and distinct perception makes its first entrance in my construal of Descartes's argument. I clearly and distinctly perceive many features in my ideas, and many relations among them. I perceive that my idea of color requires my idea of extension, and that my idea of triangularity includes the idea of three-sidedness. I also perceive that my idea of God includes my idea of infinite perfection. So what I seem to clearly and distinctly perceive among my own idcas I do clearly and distinctly perceive among my own ideas. Of course I do not know whether any objects correspond to these ideas; or if they do, whether these relations hold among them. I might be wrong about them, though I am certainly not wrong in my conceptions of them.

Thus when Descartes at the beginning of the Third Meditation claims that he is able to posit as a general rule that everything he clearly and distinctly perceives is true, we must be careful to understand him correctly. First of all, he only says he seems to be able to posit such a rule; and as he goes on to explain, the only thing he has clearly and distinctly perceived is that his ideas are in him:

But what was it about them [the earth, sky, and stars] that I perceived clearly? Just that the ideas, or thoughts, of such things appeared before my mind. Yet even now I am not denying that these ideas occur within me. But there was something else which I used to assert, and which through habitual belief I thought I perceived clearly, although I did not in fact do so. This was that there were things outside me which were the sources of my ideas and which resembled them in all respects. Here was my mistake; or at any rate, if my judgement was true, it was not thanks to the strength of my perception.9

So Descartes's alleged presupposition that everything he clearly and distinctly perceives is true is not a very hearty presupposition; it boils down to the claim that he has ideas, and that in his ideas are the qualities he thinks there are. 
Now I have found no place in the Meditations where Descartes claims that this privilege of first-person ideational reports is shown by the light of nature. But I think this can be made plausible. First, the claim is little more than claiming "I have ideas, $n$ which, as seen in the Second Meditation, follows from the claim that I think. If we know by the light of nature that I exist, as a thinking thing, then it apparently follows that there are ideas I have immediate access to, since this is what characterizes my existence as a thinking thing. Second, at the beginning of the Third Meditation, Descartes is operating under the hypothesis that he is deceived by a malevolent demon. This is his most severe doubt. Yet in considering the ideas of the sun, sky, and stars, he says that he does not now deny that those ideas are in him. In fact, this is what he perceives clearly (and takes to be true); what he denies, under this hypothesis, is that there are any real things corresponding to those ideas. Since his access to his own ideas survives the third doubt, I think it may plausibly be understood as being shown by the light of nature, given what we have said so far.

The third presupposition for Descartes's argument for God's existence and perfection can be called "the causal adequacy principle." This principle is that any cause must be at least as great as its effect. In particular, every idea must have a cause at least as great as the idea itself. Thus I cannot develop an idea of an object with property $F$ unizss the idea is drawn from something capable of generating the idca of property $F$. This does not automatically mean that every idea has a referent; rather, it means only that if I have an idea of something with a particular property, there must be something in the universe which has the ability to generate the idea of that property. It may be, for example, that I myself am capable of generating all of the ideas of properties found within my ideas.

We can see that the causal adequacy principle is supposed to be shown by the light of nature:

Now it is manifest by the natural light that there must be at least as much in the efficient and total cause as there is in the effect of that cause. 10

So it is clear to me, by the natural light, that the ideas in me are like images which can easily fall short of the perfection of things from which they are taken, but which cannot contain anything greater or more perfect."I 
It is clear that this principle of causal adequacy is really little more than the principle of sufficient reason: each cause must be sufficient for bringing about its effect.

So the three presuppositions for Descartes's argument for the existence and perfection of God are (1) the cogito, (2) the privilege of first-person ideational reports (that is, that what I seem to clearly and distinctly perceive among my own ideas, I do clearly and distinctly perceive among my own ideas), and (3) the causal adequacy principle, which is just another form of the principle of sufficient reason. It is clear that Descartes may be taken to suppose that each of these follows from the light of nature, and that there is no doubting what's shown by the light of nature.

It is interesting to juxtapose the Meditations with a work Descartes never published, suggestively titled, "The Search for Truth by means of the Natural Light." In it, Descartes apparently intends to cover much of the same material found in the Meditations. Indeed, it seems to be just like the Meditations but in dialogue form. The principle interlocutor, Eudoxus ("good belief") claims to be able to lead an unlearned man, Polyander ("everyman") to the most basic metaphysical and theological truths by the aid of the natural light alone. It is clear in this dialogue that the natural light is never to be doubted, and in fact is the sole reliable thread which can lead through these difficult investigations. Eudoxus claims it is all Polyander needs in order to gain the truth. In fact the work is subtitled

This light alone, without any help from religion or philosophy, determines what opinions a good man should hold on any matter that may occupy his thoughts, and penetrates into the secrets of the most recondite sciences. 12

Our clear and distinct perception of ideas, on the other hand, is soon shown in need of justification: we must prove God's existence and perfection in order to be certain that those ideas we clearly and distinctly perceive are ideas of real things, that is, that they genuinely refer. Unfortunately, the dialogue leaves off at a point roughly equivalent to the beginning of the Third Meditation. But I think we see from this short work that the light of nature is not something which submits to any kind of justification; and indeed, with what could we justify it? The truth of clear and distinct ideas, however, is not at all obvious, even if it is obvious that we cannot be wrong about what seems to us to be clearly and distinctly perceived. 13

12 AT X 495.

13 Note that in the Synopsis of the Meditations, Descartes claims that knowing that the mind is better known than the things of sensory experience requires "that we should know everything we clearly and distinctly understand is true in a way which corresponds exactly to our 
We turn finally to Descartes's argument for God's existence, which should be familiar. He examines his stock of ideas which purport to refer to external things, finding ideas of himself, objects, animals, other people, angels, and God. Then, armed with the causal adequacy principle, he investigates whether he could be the cause of all these ideas, or whether there is one which he necessarily could not have caused. His idea of himself is caused, of course, by himself (as he knows through the cogito). His ideas of objects can come, in short, from his idea of himself as a "thinking thing," minus the thinking part. His idea of animals can come from combinations of his ideas of things. His idea of other people can come from his ideas of animals, plus the "thinking" part of his idea of himself. His idea of angels comes from his idea of other people and his idea of Cod. But his idea of Cod, an infinite and perfect being, could come from none of these other ideas, all of which are less perfect and finite. Therefore, his idea of God can be caused only by, at the very least, something infinite and perfect-which must be Cod.

The idea seems to be that before we can conceptualize any finite, imperfect thing, we must first conceptualize an infinite, perfect "quality space"--a framework within which we can place limits and construct finite, imperfect things. This infinite, perfect "quality space," being all positive qualities to the infinite degree, is God. God is thus prior to the existence of any thing, or to the conceptualization of any thing.

This also reveals why God can be no deceiver. Being infinitely perfect makes God perfect with respect to reality, or truth. To limit God with respect to truth would be to limit God's perfection, which is absurd. Moreover, insofar as God is presupposed in my own existence, we find that I am unable to err, inasmuch as I use my God-given nature.

Now the reasoning behind these latter claims is extremely engaging and complex. I do not pretend to have done it justice here. The central point for our purposes is that the only role clear and distinct perception plays in Descartes's argument for God's existence in the Third Meditation is in uncovering Descartes's idea of God. It is more clear and distinct than any other idea he has. But this plays no immediate role in showing Cod to exist: the argument is not that everything I clearly and distinctly perceive is true, and since I have a clear and distinct idea of God, the idea must refer to a genuine object. Nor does clear and distinct perception in any way justify the immediacy of Descartes's apprehension of his own idea of God, for that has already been shown by the light of nature. Rather, Descartes has a clear and distinct idea of Cod; the light of nature (that is, the causal adequacy principle) shows that this idea must correspond to a real Cod; and since included in this idea is the inability to deceive, and since we

understanding of it; but it was not possible to prove this before the Fourth Meditation" (AT VII 13). 
have direct access to our own ideas, it has been shown that the real God is no deceiver.

We can now surely trust what we clearly and distinctly perceive (at least, once we have answered the objections raised in the Fourth Meditation), but only in regard to mathematical objects; for it has been shown only that it is impossible that 1 am being deceived by God, or by some being less powerful than God. The third doubt, the doubt which put in jeopardy our mathematical beliefs, has been dispelled; the second remains. And there is no circle here. If Descartes had claimed that God's inability to deceive justifies the light of nature, or that we know of Cod's inability to deceive only through the validity of our clear and distinct perception, then there would be a circle. But Descartes claims neither of these things.

\section{Part 3: Making way for the new physics}

In summarizing the Sixth Meditation, Descartes writes:

there is a survey of all the errors which commonly come from the senses, and an explanation of how they may be avoided; and, lastly, there is a presentation of all the arguments which enable the existence of material things to be inferred. The great benefit of these arguments is not, in my view, that they prove what they establishnamely that there really is a world, and that human beings have bodies and so on-since no sane person ever seriously doubted these things. The point is that in considering these arguments we come to realize that they are not as solid or as transparent as the arguments which lead us to knowledge of our own minds and of God, so that the latter are the most certain and evident of all possible objects of knowledge for the human intellect. Indeed, this is the one thing that 1 set myself to prove in these Meditations. 14

It seems from this passage that eliminating the second doubt, that I may be dreaming, is not that important to Descartes. For ultimately, what we gather from sensory experience is not as certain or reliable as what we know through the intellect alone. I think that in the end this is what Descartes is trying to show: that science can be based upon (what we now would call) a rationalist, or mathematical base, and not the base of ordinary experience which supported Aristotelian physics.

Descartes claims that the one goal of Meditations is to prove that what we know through our minds and through God is what we know best. 
When this insight is coupled with Descartes's mechanistic physics, and contrasted with sense-based Aristotelian physics, we can see the Meditations as an attempt to render Descartes's science more certain than, or at the very least as compelling as, its competitor. See, for example, his letter to Mersenne (1641):

I may tell you, between ourselves, that these six Meditations contain all the foundations for my physics. But please do not tell people, for that might make it harder for supporters of Aristotle to approve them. I hope that readers will gradually get used to my principles, and recognize their truth, before they notice that they destroy the principles of Aristotle. 15

Descartes is offering a new way of understanding the world, as being populated with both thinking and nonthinking things, the latter following not essences but mechanical laws. The trick, of course, is to show that there is still room for religion in such a universe, and that common sense need not be completely abandoned.

So to make this view palatable to the Aristotelians and to the theologians, Descartes has to show that this science can follow from reasonable grounds and not upset traditional Christian dogma. He of course had to do so subtly, so as not to put himself in danger. Hence the expository style of the Meditations: the pilgrim is out to show the infidel that, even on the infidel's own grounds, it can be known with certainty that there is a God and that the infidel has a soul. But in the end the grounds are not just the infidel's, but Descartes's own as well. That shift of ground was what Descartes was trying to argue for. The task was to persuade his readers that the new science, based upon those grounds, was not as heretical as some may have thought. 